\title{
Plunging Crude Oil Prices and Its Effect on Inflation in Pakistan
}

\author{
Muhammad J Shafique \\ Benazir Bhutto Shaheed University, Lyari, Karachi
}

\begin{abstract}
Pakistan has been through many phases of inflation and a tremendous amount of research is conducted. The research gap identified was the effect on inflation in Pakistan by plunging crude oil prices. This research paper focuses the impact of plunging oil prices on the Pakistan's economy during October 2011 to February 2016 with addition to other determinants of inflation in Pakistan. Pakistan is not oil producing rather oil-importing country. A major decrease in oil price should lead to low inflation. The findings showed that, the crude oil prices have no effect on the producer price index of Pakistan whereas; global economy has seen a decrease in global inflation.

Keywords: inflation, CPI, PPI, Crude oil prices, Pakistan.
\end{abstract}

\section{INTRODUCTION:}

This is not the first episode of falling oil prices. One prominent example has been the decline in oil prices from its peak level in 1980. This decline accelerated in January 1986, when Saudi Arabia ceased all attempts to prop up the price of crude oil and lifted the self-imposed restrictions on its oil production. The other prominent example in recent history is the sharp drop in oil prices after July 2008. Compared with the decline in oil prices following the Asian Crisis of 1997, these two episodes were less gradual.

The price of oil and inflation are often seen as being connected in a cause and effect relationship. As oil prices move up or down, inflation follows in the same direction. The reason why this happens is that oil is a major input in the economy. It is used in critical activities such as fuelling transportation and heating homes and if input costs rise, so should the cost of end products. Pakistan is \#34 in the world ranking for importing crude oil which makes world share of $0,4 \%$ of importing crude oil. From third quarter of 2014 (July, 2014) oil prices went down very sharply from (Tuesday 1 July 2014 OIL/USD 105.27) to $\$ 27.67$ a barrel in the first quarter of 2016 and Pakistan is a country where oil is imported for national usage as Pakistan does not produce enough oil to meet the daily required amount. Thus, the fluctuation of oil prices greatly affects the economy and especially in terms of inflation.

Globally as well as in Pakistan, not much work has been done on this respective topic. As, oil prices have direct relationship to inflation, when the oil prices in international market rise inflation should rise and if the oil prices decrease in the international market inflation rate should decrease in the Pakistan, as it is heavily dependent on the imports of oil from international market. The main research objective of this research paper is to identify that plunging oil prices should deteriorate inflation rate in Pakistan.

\section{LITERATURE REVIEW:}

A considerable amount of research has indicated that the oil price shocks have affected the real output; only a few emphasize the effects of inflation of a country. In global scenario, the effects of oil prices on the inflation appeared to decline over time. By realizing the research gap in the particular scenario of plunging crude oil prices and their effect on the inflation in Pakistan, this paper tends to investigate this phenomenon for the specific case of Pakistan. For example, (De Gregorio, Landerretche, \& Nielson 2007) found in a sample of 23 countries for 1980-2005, that a 10 per cent decrease in oil prices (in local currency) would lower inflation by around 0.2 percentage point.

Oil price declines have been followed by temporary falls in global inflation. The decline in inflation has been quite pronounced in high-income countries, the impact across countries has varied significantly, reflecting in particular the importance of crude oil prices in consumer baskets, exchange rate developments, the stance of monetary policy, the extent of fuel subsidies and other price regulations. In general, the pass-through from oil prices to inflation appears to have declined over time (De Gregorio, Landerretche \& Nielson 2007; Blanchard and Gali 2007) owing in part to the reduced oil dependence of production and consumption and a better anchoring of inflation expectations. This has significantly reduced the second round effects of oil price fluctuations on core-inflation. The dynamics of the propagation of commodity price shocks across a sample of 46 countries studied in (Pedersen, 2011) also confirmed a limited impact of oil price changes on core-inflation, contrasting with the more lasting effect of food price shocks, particularly in emerging and developing economies.

In order to gauge the likely impact of changes in crude oil prices on inflation, two simple econometric models are estimated by (Baffes, Kose, Ohnsorge \& Stocker, 2015) using data for G20 countries. The change in the price of oil was added to a standard Phillips curve model, in which inflation is a function of inflation expectations and economic loose. Second, a simple vector auto regression (VAR) model is estimated to study the dynamic interactions between headline consumer prices, producer prices, output gap, exchange rate and the price 
of oil. All regressions are country-specific and estimated at a monthly frequency over the period 2001-14. Research indicated that the pass-through to headline inflation in most cases is modest, with a $10 \%$ decline in the oil price reducing inflation by up to 0.3 percentage point at its peak impact. This is in line with other estimates in the literature. For example, (De Gregorio et al., 2007) found, in a sample of 23 countries for 1980-2005, that a 10 per cent decrease in oil prices (in local currency) would lower inflation by around 0.2 percentage point.

To be more appropriate country-specific circumstances could in some cases influence the impact of oil prices on domestic inflation. For example, for economies that import large volumes of oil, currency appreciation (depreciation) would reinforce (mitigate) the deflationary impact of the oil price decline. In countries where the government subsidizes household energy consumption, the pass-through of global oil prices to local energy prices may be dampened. (Jongwanich and Park, 2009) results indicated that, among high-income countries, the estimated impact of oil price developments on consumer price inflation is more marked in the United States than in the Euro Area or Japan, and among developing countries, more significant in India, Indonesia and Turkey than in China or Brazil, owing in part to different mixes of energy consumption, price regulations and exchange rate patterns. The impact of oil price movements on global inflation was estimated by (Baffes et al., 2015) to be essentially one-off, peaking after three to five months, before fading gradually. In particular, a $45 \%$ decline in oil prices, if sustained, would reduce global inflation by about 0.7-1.2 percentage point through 2015 .

Global researches have examined a big chunk of data and their findings are reliable and to be more relevant, if the researches conducted in the same oil importing countries had found the relation between crude oil prices and inflation like in India, then this phenomenon should also be present in Pakistan. Countries like Pakistan, which are importing oil from the international market, will be more convincing. As, (Bhattacharya and Bhattacharya, 2001) attempted to study the transmission mechanism of an increase in petroleum prices on the prices of other commodities and output a case study for India. The empirical result of paper showed that a bidirectional causality between oil and non-oil inflation in India. The most recent and relevant research was done in the neighbouring country of Pakistan i.e. India. The Indications in the researches empirically estimated the decline of crude oil prices and position of India's oil industry and especially the crude oil prices effect on India's inflation. In India, they have two popular measures of inflation: CPI (consumer price index) WPI (wholesale price index). The CPI measures prices at the retail consumer level. The WPI measures prices at the wholesale level. In regards to fuel, the WPI is more sensitive to fuel prices. It assigns a weight of $14.91 \%$ to fuelcompared to $9.49 \%$ assigned to fuel by the CPI. They also depicted the trend this year that both measures of inflation have slowed their pace. The WPI came to a halt and it was impacted by the falling crude oil prices.

The sharpest decline in prices came in the last four months - the same period when crude prices fell. The Crude Petroleum Index is used as an input to calculate the WPI. It has been declining since August 2014. Its sharpest decline was seen in November - the index slumped $16.6 \%$. A fall in fuel prices also impacts food prices as transportation costs come down. Food articles account for $14.3 \%$ of the WPI and $39.7 \%$ of the CPI. As a result, the impact of diminishing crude oil prices is magnified.

(Jain and Patil, 2015, p. 568)

(Khan, 1995) investigated the macroeconomics determinants of high inflation. They quantified and identified the responsible factors for inflation in Pakistan. The key factors identified by this study were: (a) supply shock (deviation of total availability of goods from its normal trend); (b) monetary policy shocks (use of cash balance or credit creation to finance budget deficit); (c) tax policy shocks (sales and excise duties); (d) external shocks (effect of exchange rates); (e) pricing policy shocks (procurement price of wheat, cotton, and sugar and the administered prices of fuel, gas, and electricity); and (f) expectations. (Khan and Mohammad, 1996) estimated an overall inflation equation along with CPI food price inflation and CPI non-food price inflation equations. The study was based on time series data covering the period from 1971 to 1995 . The study concluded that the money supply positive relation with both type of inflation in Pakistan due to loose monetary policy. They also concluded that there exist a stable long-run equilibrium relationship between inflation, money supply (M2 definition), import price, and real GDP. (Khan and Gill, 2010) have adopted time series data from 1971 to 2005 and employed Ordinary least square method for analysis of determinants of inflation in Pakistan using different price indicators i.e. CPI, WPI, SPI and GDP Deflator.

Researches all around the globe have found that the decline in crude oil prices in the international market have a direct impact on the inflation of a country. Recently, from June 2014 to January 2016 whether; the countries are of G-20 or developing countries with a difference of intensity contributing to the decrease in global and country-wise inflation varying in intensity. In the light of previous literature, author saw that there was less research work done on the relation of crude oil prices and inflation and in the case of Pakistan, no significant work was available. Whereas, it did not have any positive effects on inflation in Pakistan as they should have. Unfortunately, in a country like Pakistan it would have greatly affected the economy and have caused GDP to grow drastically, but the case is totally inverted as the inflation did not reacted to the scenario as it was expected and seen throughout the world. The crude oil prices plunged from \$105.27 per barrel in June 2014 to $\$ 27.67$ per barrel January 2016, but inflation rate increased throughout this period against the researches that have been 
conducted world-wide in this domain.

\section{MODEL AND METHODOLGY:}

Hypothesis:

$\mathbf{H}_{\mathbf{a}}=$ Plunging crude oil prices have no effect on inflation in Pakistan.

$\mathbf{H}_{\mathrm{b}}=$ plunging crude oil prices have an effect on inflation in Pakistan.

VARIABLE RELATIONSHIP MODEL:

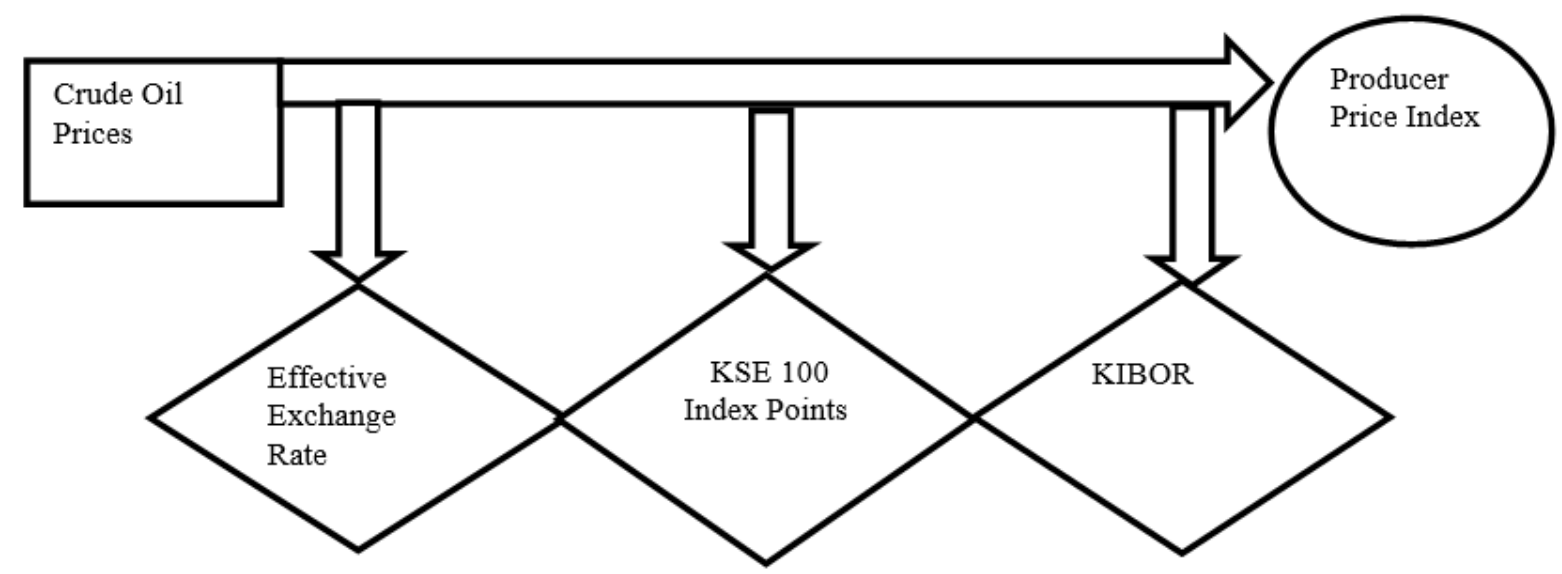

VARIABLES:

INDEPENDENT VARIABLE:

There is one independent variable in this research paper that is Crude Oil Prices. Crude oil prices are tested as independent variable to measure if there is a relationship between Crude Oil Prices and the dependent variable Producer Price Index. Taking crude oil prices have a very significant role as many researches are conducted to find the relationship between cop and inflation.

\section{DEPENDENT VARIABLE:}

To measure the relationship between COP and Inflation, the indicator used for inflation is Producer Price Index (PPI). The Producer Price Index (PPI) is a weighted index of prices measured at the wholesale, or producer level. A monthly release from the Pakistan Bureau of Statistics (PBS), the PPI shows trends within the producer markets from manufacturing industries to commodities markets. All of the physical goods-producing industries that make up the Pakistan's economy are included. PPI is the dependent variable taken in this paper. As to match the data of COP's with cost push inflation the effect would be on the producer and PPI is the suitable indicator of producer level inflation.

\section{CONFOUNDING VARIABLES:}

GDP, Effective exchange rate and Interest rate are the three variables that are confounding variable found in the respective research. Gross domestic product (GDP) is the monetary value of all the finished goods and services produced within a country's borders in a specific time period. Though GDP is usually calculated on an annual basis but due to low number of observations a proxy for GDP, Karachi Stock Exchange 100 Index (KSE-100 Index) points is used to get the monthly data. KSE-100 Index is a stock index acting as a benchmark to compare prices on the Karachi Stock Exchange (KSE) over a period. In determining representative companies to compute the index on, companies with the highest market capitalization are selected. Effective Exchange Rate is an index that describes the relative strength of a currency relative to a basket of other currencies. Suppose a country has trading partners and denote and as the trade and exchange rate with country respectively. Here, effective exchange rate data is taken to analyse the effect on PPI. Interest rate the proportion of a loan that is charged as interest to the borrower, typically expressed as an annual percentage of the loan outstanding. Here proxy of interest rate KIBOR is taken as to increase the number of observations. It is Karachi Inter Bank Offer Rate (KIBOR), given by specialized institution on daily, weekly, monthly and on 1, 2 and 3 yearly basis to all the commercial banks of Pakistan so that they charge interest to their customers on that basis. This rate is inflation adjusted rate and then banks by adding 2 or $3 \%$ in KIBOR rate charge their customers for their profit.

\section{METHODOLOGY:}

Here we test all the variables for unit root to find whether simple regression analysis can be run or not. Firstly, augmented Dickey-Fuller test was used for testing unit root test on the independent variable Crude oil Prices and findings showed that it has a unit root and data is not stationary.

Independent variable PPI is also tested for unit root. Augmented Dickey-Fuller test was used and unit 
root was also found in the PPI data.

\section{Null Hypothesis: PPI has a unit root}

Exogenous: Constant

Lag Length: 1 (Automatic based on SIC, MAXLAG=10)

Augmented Dickey-Fuller test statistic

Test critical values:

\begin{tabular}{cc} 
& -2.375381 \\
\hline $1 \%$ level & -3.565430 \\
$5 \%$ level & -2.919952 \\
$10 \%$ level & -2.597905
\end{tabular}

*MacKinnon (1996) one-sided p-values.

All the confounding variables i.e. KSE 100 Index points, Effective Exchange Rate and KIBOR were also tested for the unit root by Augmented Dickey-Fuller test and empirical findings showed that, all variables except effective exchange rate have a unit root. Therefore, simple regression analysis cannot be used for further analysis.

Null Hypothesis: EXR has a unit root

Exogenous: Constant

Lag Length: 0 (Automatic based on SIC, MAXLAG=10)

t-Statistic

Prob.*

Augmented Dickey-Fuller test statistic

$-5.604985$ 0.0000

\begin{tabular}{ccr}
\hline Test critical values: & $1 \%$ level & -3.562669 \\
$5 \%$ level & -2.918778 \\
$10 \%$ level & -2.597285
\end{tabular}

*MacKinnon (1996) one-sided p-values.

Null Hypothesis: KSE has a unit root

Exogenous: Constant

Lag Length: 0 (Automatic based on SIC, MAXLAG=10)

t-Statistic

Prob.*

Augmented Dickey-Fuller test statistic

$-1.362616$

0.5934

Test critical values:

$1 \%$ level

$-3.562669$

$5 \%$ level

$-2.918778$

$10 \%$ level

$-2.597285$

*MacKinnon (1996) one-sided p-values. 
Null Hypothesis: INT has a unit root

Exogenous: Constant

Lag Length: 2 (Automatic based on SIC, MAXLAG=10)

Augmented Dickey-Fuller test statistic

Test critical values:

$\begin{array}{cc}1 \% \text { level } & -3.568308 \\ 5 \% \text { level } & -2.921175 \\ 10 \% \text { level } & -2.598551\end{array}$

*MacKinnon (1996) one-sided p-values.

Johansen co-integration test was used after knowing that the time series data collected is non-stationary. Co-integration means that, while many developments can cause permanent changes in the individual variable, there is some long-run equilibrium relation tying the individual variables together, represented by some linear combination of them. The Johansen test approaches the testing for co-integration by examining the number of independent linear combinations for time series variables set that yields a stationary process. The Johansen test has two forms: the trace test and the maximum eigenvalue test. Trace test is used to interpret the results. Unrestricted Co-integration Rank Test (Trace)

\begin{tabular}{|c|c|c|c|c|}
\hline $\begin{array}{l}\text { Hypothesized } \\
\text { No. of CE(s) }\end{array}$ & Eigenvalue & $\begin{array}{l}\text { Trace } \\
\text { Statistic }\end{array}$ & $\begin{array}{c}0.05 \\
\text { Critical Value }\end{array}$ & Prob.** \\
\hline None $*$ & 0.591259 & 96.37023 & 69.81889 & 0.0001 \\
\hline At most $1 *$ & 0.453905 & 49.84716 & 47.85613 & 0.0321 \\
\hline At most 2 & 0.197819 & 18.38908 & 29.79707 & 0.5374 \\
\hline At most 3 & 0.090546 & 6.927155 & 15.49471 & 0.5861 \\
\hline At most 4 & 0.037579 & 1.991765 & 3.841466 & 0.1582 \\
\hline
\end{tabular}

Trace test indicates 2 co-integrating eqn(s) at the 0.05 level

* denotes rejection of the hypothesis at the 0.05 level

**MacKinnon-Haug-Michelis (1999) p-values

Tests showed that, null hypothesis is rejected in Johansen co-integration test and the data is cointegrated through the trace statistic value. The listed variables are co-integrated in the long run and therefore, we can use Vector Error Correction Model.

PPI

COP

1.000000

0.525187

KSE

\section{EXR}

INT

The coefficients of the variables shown in the table above define the existence of relationship between the variables. Most importantly, relationship between the PPI and COP and the magnitude of the change can also be measured.

\section{FINDINGS}

Augmented Dickey-Fuller test showed the data of all the variables is non-stationary except the data of Effective Exchange Rate as the p-value is less than the alpha i.e. 0.05 or 5\%.The Johansen co-integration test found that there is co-integration in the data by checking the p-value which is less than the alpha i.e. 0.05 or $5 \%$.

Findings showed that, there is an inverse relationship between COP and PPI which means that, when COP will plummet by 0.525 , PPI will rise by 1.000 .

\section{CONCLUSION:}

All the relevant tests and their findings show that there is a relationship between the independent (COP) and dependent (PPI) but the interesting fact which was found that the relationship was inverse. As, this research 
paper was keen to find that which type of relationship exists between the plunging crude oil prices and inflation in Pakistan. As, the results showed that, there exists an inverse relationship between plunging crude oil prices and inflation which is quite amazing and thoughtful that while, all around the globe the relationship between Crude oil Prices and inflation is direct and inflation rises with the rise in crude oil prices and vice versa, then why does the relationship became inversed in the situation of Pakistan.

\section{REFERENCE LIST:}

Baffes, J., Kose, A.M., Ohnsorge, F., Stocker, M. (2015). The Great Plunge in Oil Prices: Consequences and Policy Responses. World Bank Group, Policy Research Note PRN/15/01.

Bhattacharya, K. \& Bhattacharya, I. (2001). Impact of Increase in Oil Prices on Inflation and Output in India', Economic and Political Weekly, 36(51), 4735-4741.

Blanchard, O. J. and J. Galí. (2007). The Macroeconomic Effects of Oil Price Shocks: Why are the 2000s so different from the 1970s? NBER Working Paper No. 13368.

De Gregorio, J., and O. Lenderretche, and C. Neilson. (2007). Another Pass-Through Bites the Dust? Oil Prices and Inflation. Central Bank of Chile Working Paper No. 417.

Jain, S.A, and Patil, S.N. (2015). Crude oil prices and its impact on Indian economy. International Journal of Social Science and Humanities, Research vol. 3, Issue 2, pp: (562-572).

Jongwanich, J. and D. Park, (2009). Inflation in developing Asia. Journal of Asian Economics 5: 507-518.

Khan, A. H \& Mohammad, A. Q, (1996). Inflation in Pakistan Revisited. The Pakistan Development Review 35(4), 747-759.

Khan, A. H., Hafiz A. P., \& Muhammad, A. R. (1995). What Explains the Current High Rate of Inflation in Pakistan? The Pakistan Development Review, 34(3), 927-943.

Khan, R. E. A. \& Gill, A. R. (2010). Determinants of Inflation: A Case of Pakistan (1970 - 2007). Journal of Economics, 1(1), $45-51$.

Pedersen, M. (2011). Propagation of Shocks to Food and Energy Prices: An International Comparison, mimeo, Central Bank of Chile.

Qayyum, A. (2006). Money, Inflation, and Growth in Pakistan. The Pakistan Development Review, 45(2), 203212 . 